\title{
Highly Efficient Milling on the Example of Selected Machining Strategies
}

\author{
Kazimierz Zaleski', Jakub Matuszak ${ }^{1 *}$, Andrzej Zyśko \\ 1 Lublin University of Technology, Faculty of Mechanical Engineering, ul. Nadbystrzycka 36, 20-618 Lublin, \\ Poland \\ * Corresponding author's e-mail: j.matuszak@pollub.pl
}

\begin{abstract}
The pursuit to achieve a broadly defined optimisation of the manufacturing processes imposes the use of the increasingly innovative machining methods. The increase of the machining efficiency, assuring a high surface quality as well as precision of dimensions and shapes, necessitates the search for new methods to meet the demanding requirements, apart from the development of materials used for the working parts of tools, wear-resistant coatings or improvement of the cutting tool point geometry. One of the methods to improve forming by machining is the optimisation of the machining strategy during the manufacture of the components having complex shapes. The progress in this field is particularly noticeable along with development of the software for machining on multi-axis machines. This article presents the results of tests for the impact of machining strategy on passive force, cutting torque, material removal rate, topography of the obtained surface and the shape of chip resulting from the aluminium alloy milling. The tests were performed by comparison of the classic strategy available in the NXCAM system to the iMachining technology.
\end{abstract}

Keywords: passive force, cutting torque, iMachining, milling strategy.

\section{INTRODUCTION}

The dynamic development of machines, tool materials and tool design solutions enabled milling to be the last operation performed in the product forming process, even for the materials after heat treatment. The numerically controlled machines enable automation of the manufacturing processes. Much attention is paid to optimise the machining in a way that should result in obtaining the best possible surface quality and increasing the efficiency, which reduces the machining time. This is related to the selection of appropriate machining strategy. The most popular are such machining methods as: HSC associated with the finishing operations, and HPC intended to maximise the material removal rate. The CAM system manufacturers offer various types of machining strategies tailored to the machining methods. In the case of HPC machining, the general assumptions cover minimisation of idle movements, maximum use of the tool working point, smoothing of the machining paths, etc. High efficiency of machining is especially required in the case of the thin-wall components used in the aviation industry, when sometimes a finished part constitutes less than $10 \%$ of the initial semi-product volume.

The authors of this study [1] analysed the impact of the machining strategy on the accuracy of dimensions and shape as well as the surface roughness while milling the thin walls made of Ti6AI4V titanium alloy. When machining a $1 \mathrm{~mm}$-thick wall, four different machining strategies were tested. It was observed that while applying the strategy that consisted in machining of the wall in two passes (one per each side of the wall), vibration occurred, which resulted in a significant increase of roughness in the upper part of the wall (on the area being most distant from the fastening). On the other hand, the optimal approach as regards obtaining the highest dimensional accuracy was the alternate strategy 
with the smallest machining depth $\mathrm{a}_{\mathrm{p}}=3 \mathrm{~mm}$ used during the experiment. However, this strategy resulted in the smallest volume efficiency.

The article [2] includes the analysis of the impact of down milling and up milling on the surface roughness (Rz parameter) of a $10 \mathrm{~mm}$ thick wall made of $\mathrm{C} 45$ steel. The mathematical model was elaborated to consider the engineering parameters of milling that proved to be highly compliant with the measurement results. On the basis of the simulation and the experiment, it was proven that better surface quality was obtained as a result of down milling.

In the aviation and automotive industry, milling is frequently performed on free surfaces. In order to obtain a good quality of surfaces, the machining paths of the ball-shaped cutter must be concentrated. The study [3] includes the analysis pertaining to the impact of the ball-shaped cutter angle in relation to the machined surfaces of thin walls on the accuracy of dimensions and shape. The angles of 15, 20, 30, 40 and 45 degrees were selected for the tests. It was proven, both by FEM simulation (Finite Element Method) and during the test experiment that the least strain of a $2 \mathrm{~mm}$ thick wall was obtained when applying the angles of 15 and 45 degrees. In the study [4], the new milling strategy for free surfaces was

proposed to increase the cutting edge durability while milling the hard-to-machine nickelbased alloy (GH4169). Such a strategy consists in the active control of the ball-shaped cutter working part involvement. The concept anticipated that the ball-shaped part of the cutter would split into segments and the angle of the cutter would change while milling in relation to the workpiece for the purpose of full use of the working part. This allowed to increase the tool durability. The problem with the tool wear is also mentioned in the study [5], in which the authors investigated the impact of the microstructure of cutters made of sintered carbides on the durability while milling the titanium-based Ti6Al4V alloy. It was proven that the tools having the ultra-fine-grained structure show the highest durability, especially crash wear resistance.

The problem with choosing the optimum strategy for milling a pocket is discussed in the study [6]. The impact of such factors as cutting speed, feed per tooth, cutting depth and width on the machine effects was analysed as well. The parameters were optimised and chosen on the basis of the Taguchi method. The spiral strategy proved to be the best one out of the three strategies for milling a pocket.

The analysis of the machining strategies during HSM (high speed milling) of forms and dies is discussed in the publications $[7,8]$. The shape complexity of the elements of this type requires appropriate machining strategies. It was found that the manufacturing process by the HSM method should be analysed upon dividing the machining into the following stages: rough machining, semi-finishing and finishing. The issue of optimization as regards obtaining the best quality and the milling cutter durability should cover such aspects as: shape, size and local curvature of the workpiece, geometry of the milling cutter and engineering parameters of machining.

Machining of rotors or skew gears is one of most complicated machining processes [9]. It usually requires 5 -axis machines and optimisation of tool paths. The issues related to searching for the tools with the possibly largest diameter for machining the rotors to increase the machining efficiency are analysed in the publication [10]. In turn, the concept of searching for the optimum strategy for rotor machining based on minimum machining force is analysed in the publication [11].

A popular method of slot milling is trochoidal milling. This method assumes the use of larger axial milling depths $a_{p}$ and smaller milling widths $\mathrm{a}_{\mathrm{e}}$. This gives many advantages, such as: better use of the working part, smaller values of forces in the radius direction. The authors of the publication [12] analysed the impact of the trochoid step on such indicators as machining force and vibration amplitude. The milling speed and the trochoid lead were proven to have a significant impact on the machining effects.

The element surface quality after milling is one of the key factors. Many authors were raising the problem of machining strategy optimisation as regards the surface quality improvement $[13,14,15,16,17,18,19]$.

One of the machining strategies that gains significant popularity it the iMachining strategy that is in line with the existing trend for shortening the workpiece milling time. In the publication [20], the authors analysed the cooling manner impact on the cutting edge durability while milling the S235JR steel with the iMachining method. It was observed that the use of traditional method of cooling by flooding had an adverse impact on the solid carbide milling cutters. 
In this article, an attempt was made to compare the conventional strategy to the iMachining strategy as regards process efficiency, chip shape, surface roughness, passive force and cutting torque.

\section{METHODOLOGY}

Milling was performed on the Avia VMC800HS vertical machining centre with the Heidenhain iTNC 530 control system having the maximum rotational speed of spindle $\mathrm{n}=24000 \mathrm{rpm}$ and maximum plane motion speed of $40 \mathrm{~m} / \mathrm{min}$.

The workpiece was a $220 \times 170 \times 65 \mathrm{~mm}$ specimen of EN AW 7075 T651aluminium alloy. The tests were conducted using the FRAISA $10 \mathrm{~mm}$ dia. double-bit flycutter (symbol C15520.450) made of sintered carbides with Celero wear-resistant coating. In order to generate the paths of the tool machining strategy chosen, the Siemens NX 10 software with the iMachining overlay of SolidCam make was applied. Fig. 1 shows the test stand lay-out.

The changing factors during milling were: the type of applied machining strategy and the machining parameters that were adjusted to different values of machining depth $a_{p}$ and width $a_{e}$ being characteristic for the chosen machining strategy. The model of a part on which the abovementioned engineering tests were conducted is presented in Fig. 2.

The first experiment was performed using the standard strategy. The manufacturer-recommended parameters were applied, i.e. $\mathrm{n}=12000 \mathrm{rpm}$, $\mathrm{v}_{\mathrm{f}}=2000 \mathrm{~mm} / \mathrm{min}$. The machining depth for a single path was established for the constant level

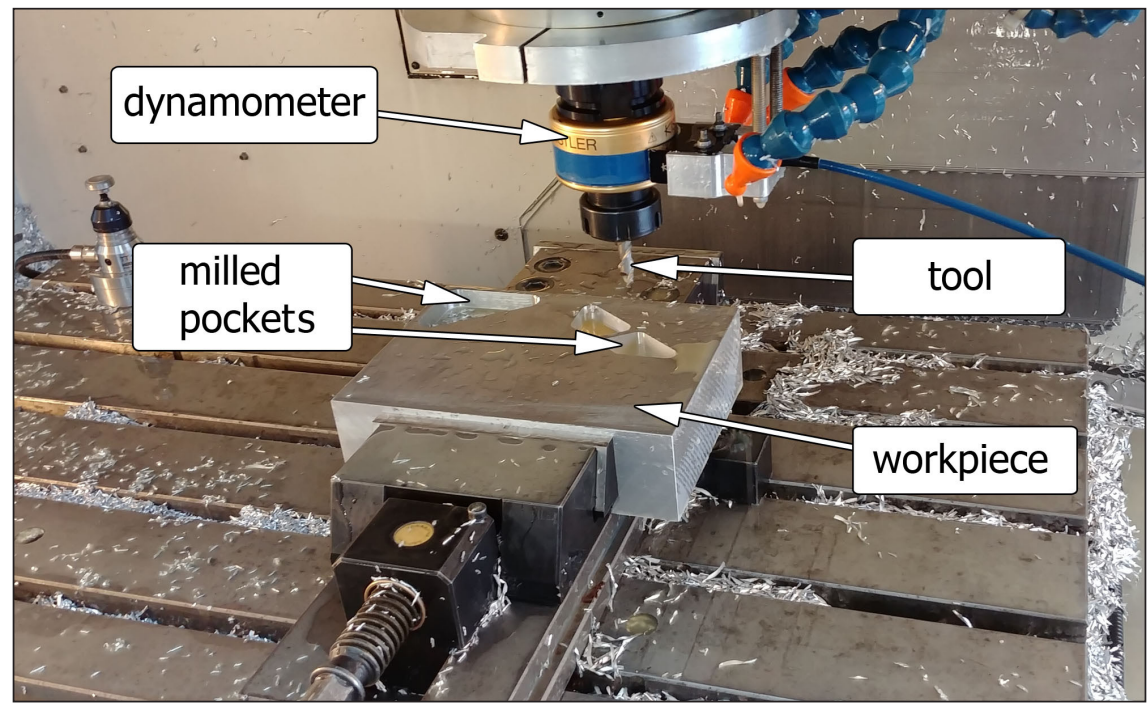

Fig. 1. Test stand lay-out
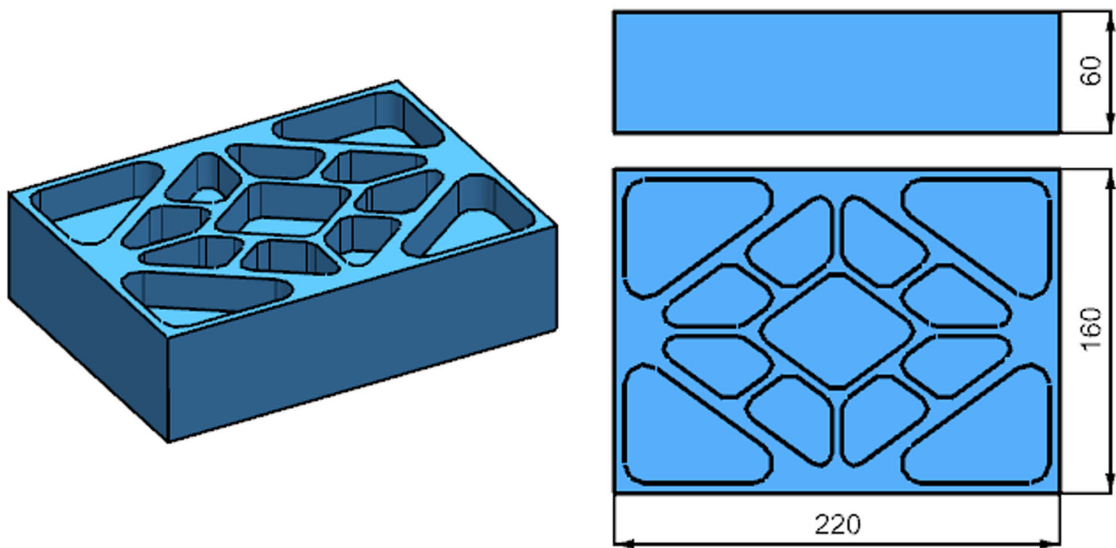

Fig. 2. Model of a part used for the test 
of $2 \mathrm{~mm}$. The parameters were adjusted to the technical capabilities of the machine and the applied tool.

The second experiment was conducted on the same semi-product using the iMachining strategy. In accordance with the characteristics of this strategy, the machining depth of $20 \mathrm{~mm}$ was applied to make use of the entire cutting edge length. The technology of the applied strategy enables to automatically select the rotational speed of the spindle and its rate of feed owing to the automatic cutting parameter selection creator. Any change of such parameters is possible through the so-called machining intensity level, the value of which is from 1 to 8 . As the rate of feed is changing at the time of machining and its value is adjusted to the geometry being currently machined, only the input parameters of the tool can be determined, i.e. $\mathrm{n}=12000 \mathrm{rpm}, \mathrm{v}_{\mathrm{f}}=2000 \mathrm{~mm} / \mathrm{min}$. The default and recommended level of machining intensity is 3 . However, after the machine rigidity analysis and the initial testing performance, the machining intensity level was established to be 6 .

The whole experiment was carried out using a cutting fluid.

The passive force and the cutting torque were measured using the Kistler 9125A rotary force gauge (Winterthur, Switzerland). In the measurement path, the force gauge was combined with the 5237A1/A2 actuator and the DAQ 5697A data acquisition block.

The weight loss was determined using the analytical balance having the accuracy of $0.01 \mathrm{mg}$.

The surface topography was analysed on the T8000RC120-400 profilographometer provided by Hommel-Etamic. The roughness was measured on the pocket bottom, upon previous removal of the wall to enable access of the gauging point of the head. The schematic diagram of the experiment is shown in Figure 3.

The following factors were compared during the tests: machining time of workpiece pocket, lay patterns, surface roughness, form and shape of chips, factor of volume occupied by chips, passive force and cutting torque at the time of machining.

\section{RESULTS}

Figure 4 presents the view of an element made in accordance with the iMachining strategy. The pocket-type structures in which a significant portion of material is removed while machining is characteristic for the aviation industry.

In order to compare the machining effects, the objects having the same geometry were made using the conventional strategy, the same machine, tool and technological tooling.

\section{Impact of technology on machining time and material removal rate MRR}

By analysing the machining times for particular strategies that amounted to $20.52 \mathrm{~min}$ utes for the standard strategy and $11.12 \mathrm{~min}$ for the iMachining strategy, it can be stated that the time saved, in case of the example above, is approx. $85 \%$.

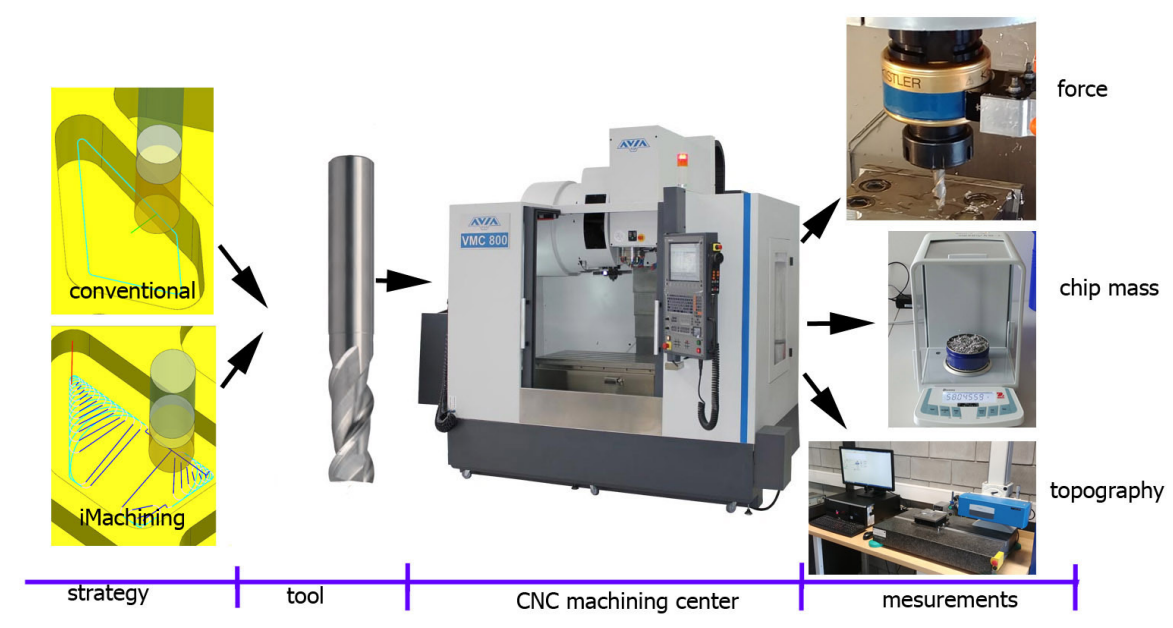

Fig. 3. Schematic diagram of the experiment 


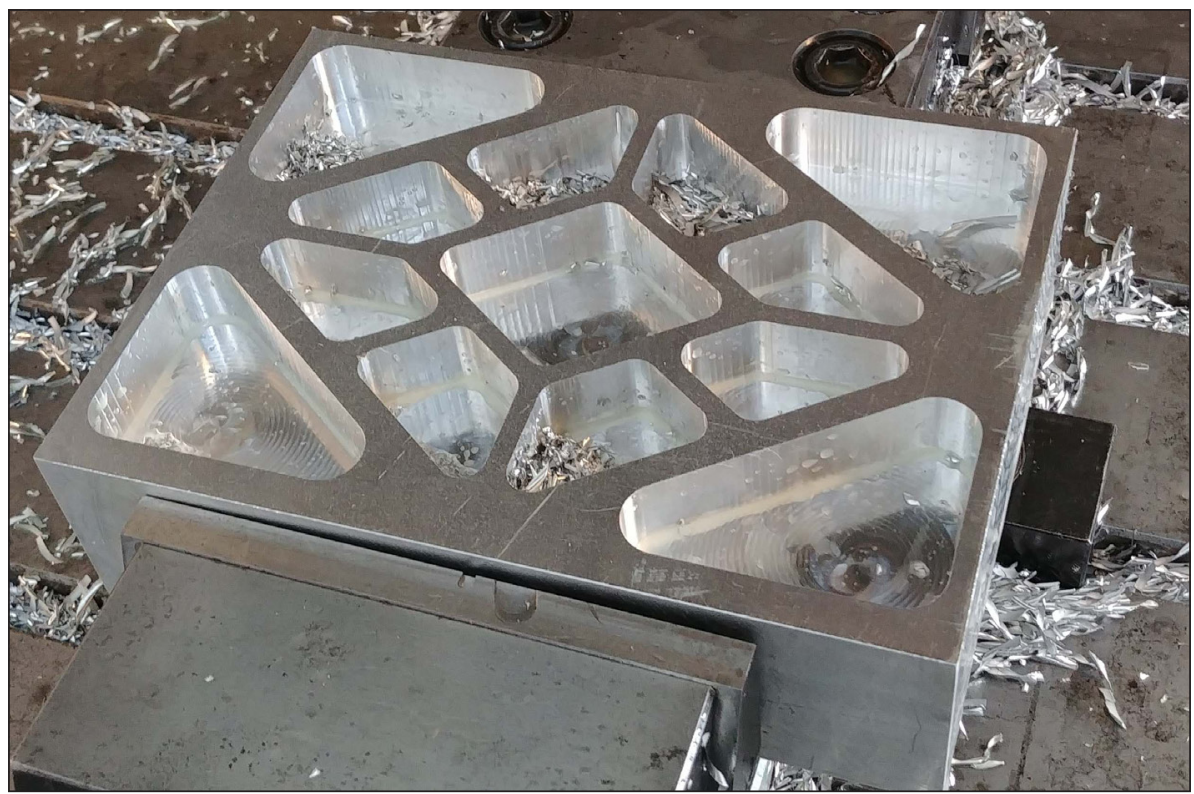

Fig. 4. View of workpiece after milling

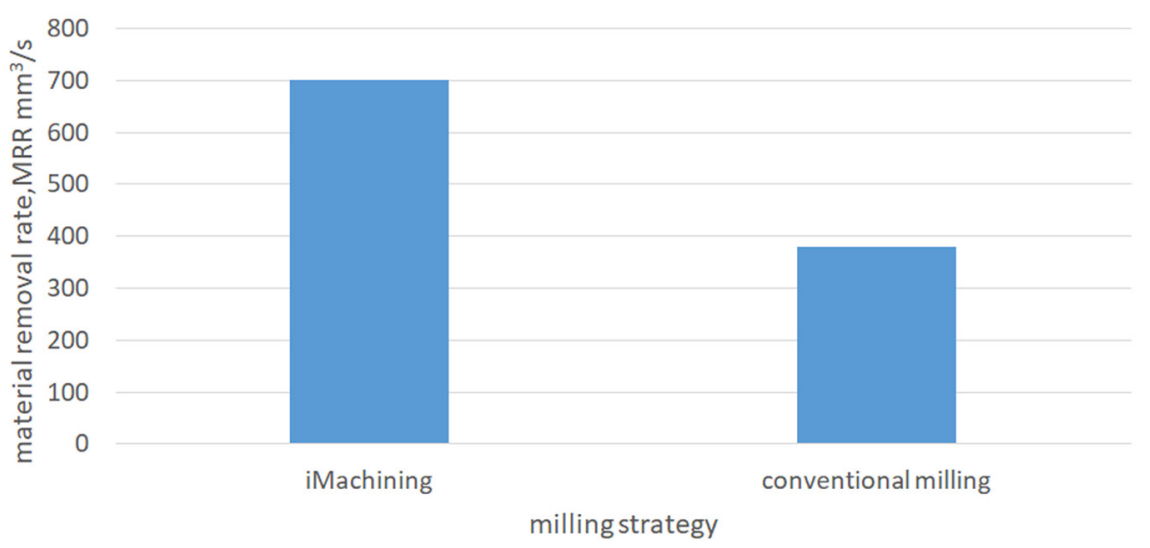

Fig. 5. Comparison of material removal rate MRR

\section{Impact of technology on the surface quality}

A significant parameter that determines the part manufacture is the surface quality, and namely its roughness that is determined by such parameters as: Ra, Rz. In the experiment, the rough machining was applied, after which the finishing process often takes place and despite this, for a significant quantity of part, this is most often the final machining and the resultant surface quality remains on the final product. In the conducted experiment, both machining strategies resulted in a similar surface condition, although iMachining took significantly less time (Fig. 6). This allows to state that the machining can be performed in a more effective manner without significantly impairing the roughness parameters.
Figure 7 shows the surface topography after the applied machining methods. For the iMachining strategy, not only the signs of the cutting edge feed were visible but also the signs of subsequent tool passes on the specimen face. In turn, in the case of the conventional machining, the signs of subsequent application of the cutting edge (reflection of the cutting edge feed) were visible. Upon analysing the surface parameters, it was found that smaller roughness was obtained after iMachining (parameters: Sa and Sz).

Figure 8 presents the view of surface roughness profile for the applied strategies. There are signs of subsequent tool passes visible in the case of the iMachining strategy. 

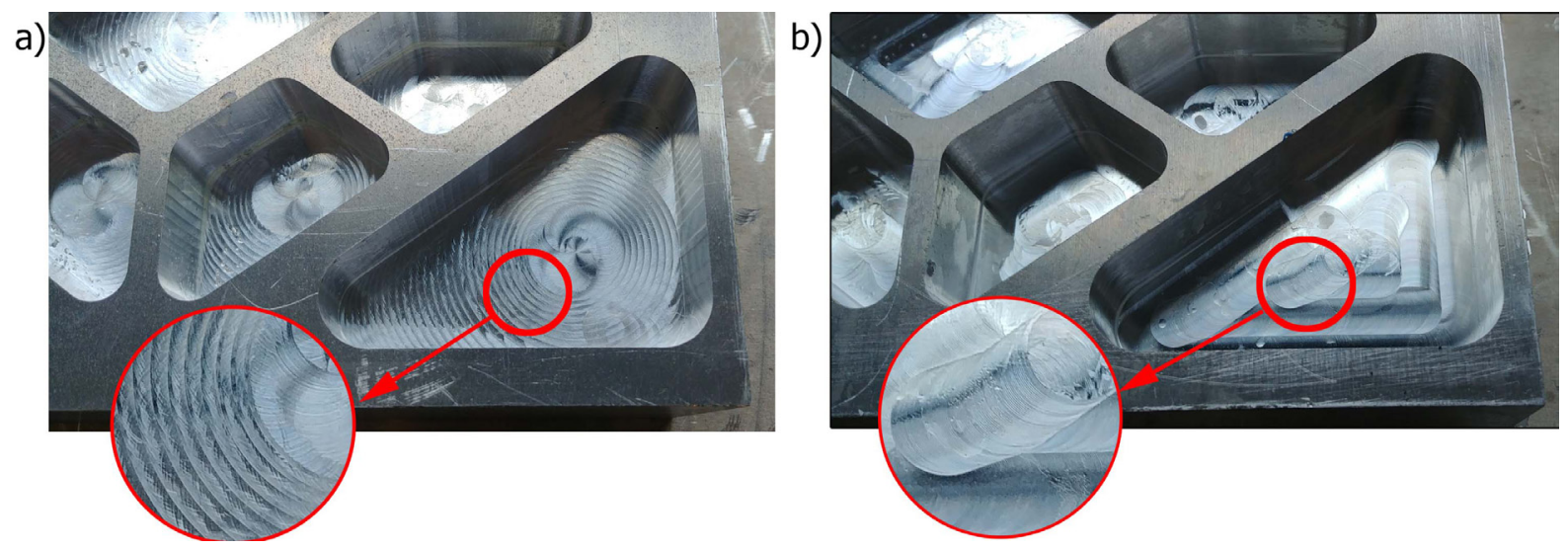

Fig. 6. View of part after machining: a) iMachining, b) conventional method

a)

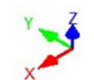

$\mathrm{Sa}=0,336 \mu \mathrm{m} ; \mathrm{Sz}=3,23 \mu \mathrm{m}$ b)
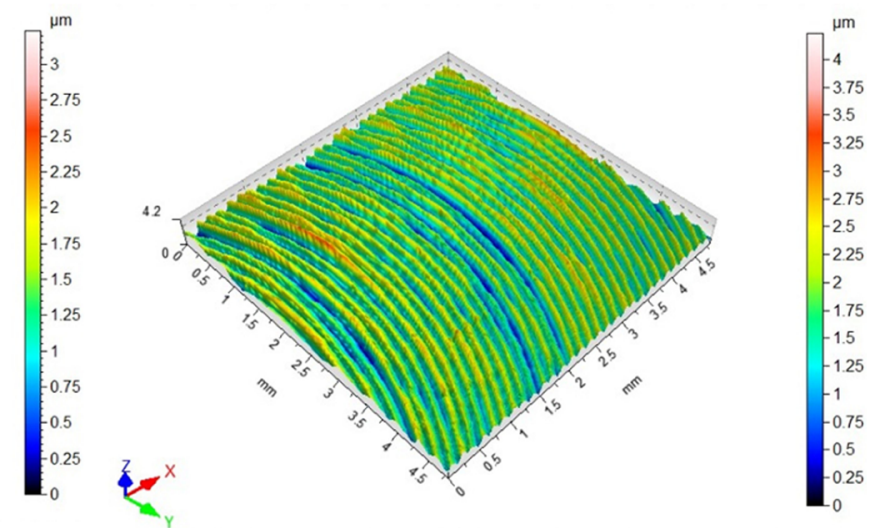

$\mathrm{Sa}=0,385 \mu \mathrm{m} ; \mathrm{Sz}=4,23 \mu \mathrm{m}$

Fig. 7. View of surface topography after machining: a) iMachining strategy, b) conventional strategy

a)

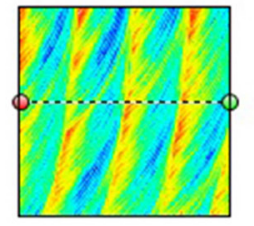

Extracted profile

b)

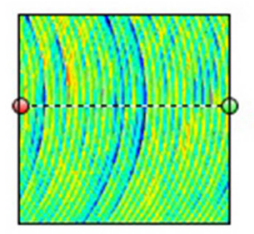

Extracted profile
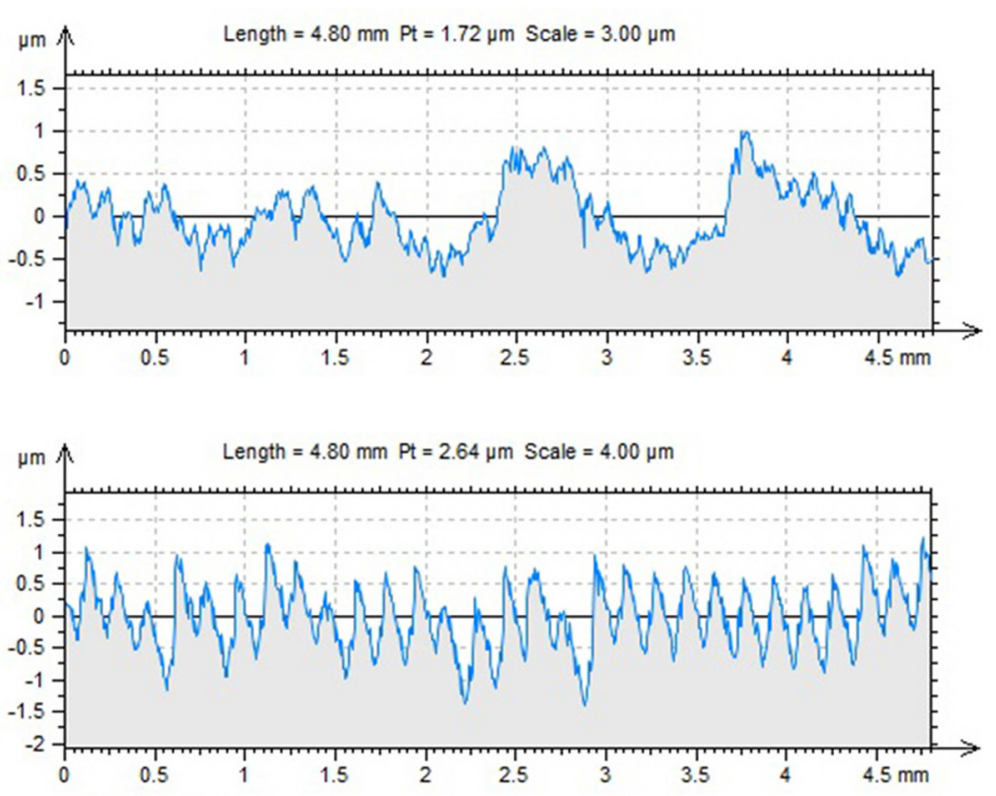

Fig. 8. View of roughness profile after machining: a) iMachining strategy, b) conventional strategy 


\section{Impact of technology on the chip shape and form}

Figure 9a presents the exemplary shapes of chips resulting from machining the EN AW 7075 T651 aluminium alloy that is milled by means of Fraisa tools with the iMachining method. There is a significant difference between the shape of such chips and the form of chips presented in Figure $9 b$ that resulted from conventional technology machining. The chips originating from iMachining have a more repeatable shape and are more twisted. In turn, the chips after conventional machining have the reduced dimensions. The chip shape depends on many different factors, such as: geometry of the applied cutting tools, type of the material machined, technological conditions of machining.

For the chips that originated while machining per two strategies, the chip volume factor $\mathrm{k}_{\mathrm{ch}}$ was determined, expressed as the ratio of volume occupied by chips $\mathrm{V}_{\mathrm{ch}}$ to the volume of the same weight of solid material $\mathrm{V}_{\mathrm{m}}$ :

$$
\mathrm{k}_{\mathrm{ch}}=\frac{\mathrm{V}_{\mathrm{ch}}}{\mathrm{V}_{\mathrm{m}}}
$$

Figure 10 shows the values of the determined factor. The factor was 16.5 for the conventional machining and 35.4 for the iMachining, which weights in favour of the conventional machining as regards the intensity of filling the collective containers with chips in the production plant.

Due to high efficiency and intensity of HSC and HSM machining, the shape and form of chips is highly important for their quick evacuation from the machining zone. This is very crucial for the machining process performance safety and the applied tool durability. When milling the closed pocket structures, there is a

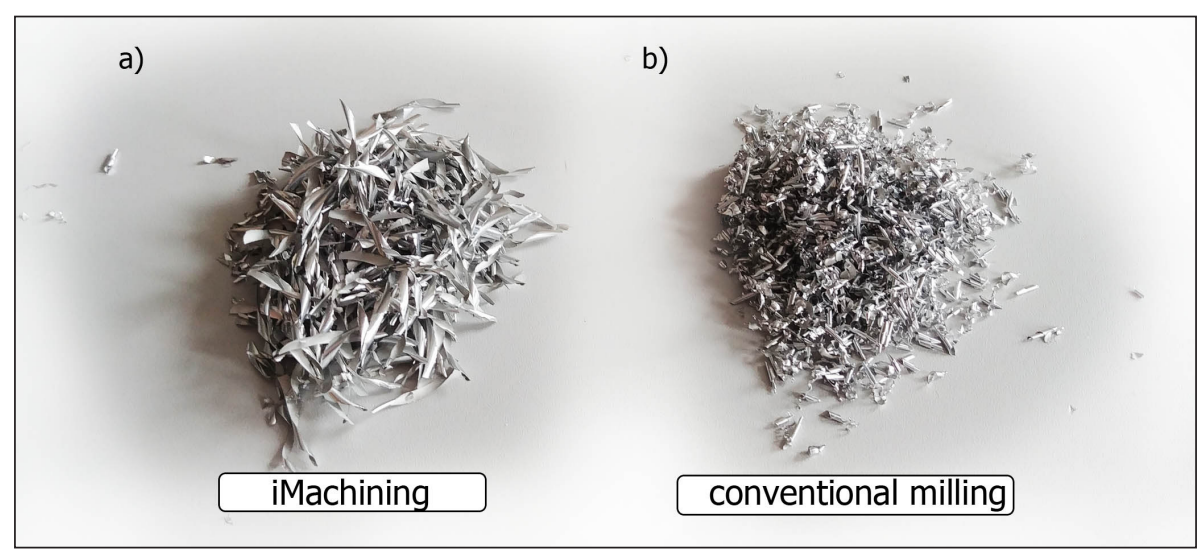

Fig. 9. Chip shape resulting from machining by: a) standard technology $\left(a_{p}=2 \mathrm{~mm}\right.$, $\left.\left.\mathrm{n}=12000 \mathrm{obr} / \mathrm{min}, \mathrm{v}_{\mathrm{f}}=2000 \mathrm{~mm} / \mathrm{min}, \mathrm{a}_{\mathrm{e}}=7,5 \mathrm{~mm}\right), \mathrm{b}\right)$ iMachining $\left(\mathrm{a}_{\mathrm{p}}=20 \mathrm{~mm}, \mathrm{n}=12000 \mathrm{obr} / \mathrm{min}\right)$

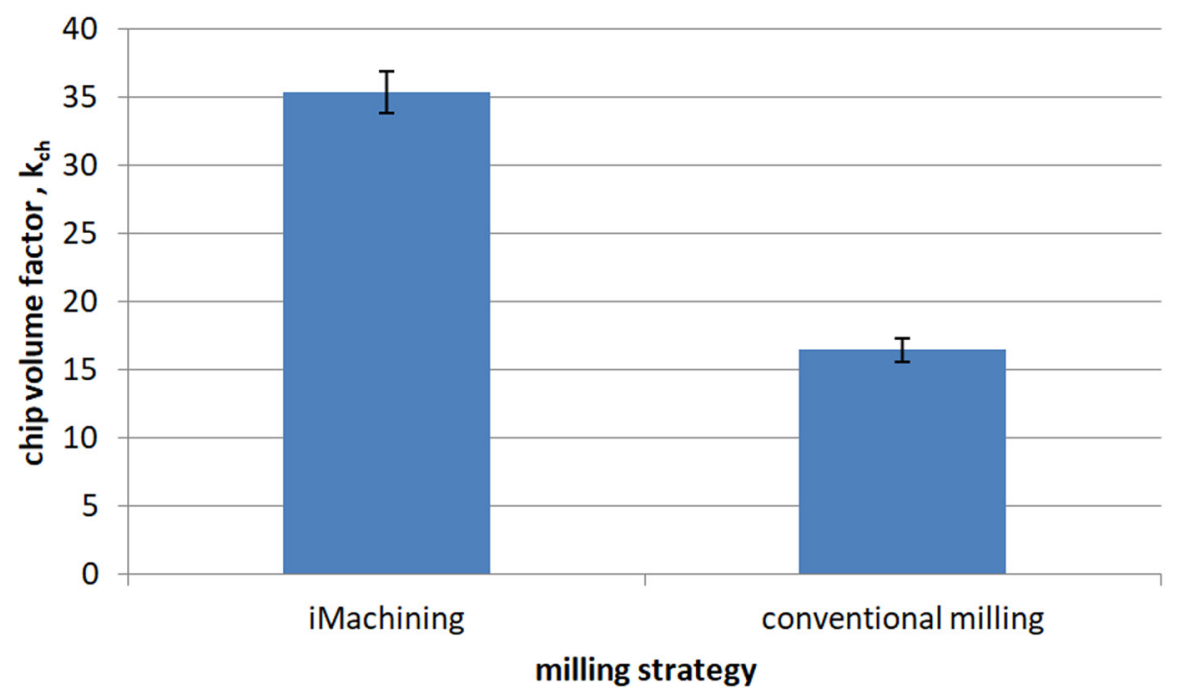

Fig. 10. Comparison of the chip volume factor values 
risk that chips will be trapped in the pockets and their removal will be rendered difficult. A greater value of the factor of volume occupied by the chips makes the chip removal from the machining zone, especially from the closed pockets, by means of liquids or gases, more efficient in the case of iMachining.

\section{Impact of technology on the machining force and torque}

Certain characteristic zones can be distinguished when machining the pockets in accordance with the iMachining strategy. The tool paths for particular zones are presented in Figure $11 \mathrm{a}$, while the corresponding passive force runs are shown in Figure 11b. Zone A is the zone of tool penetration to the full machining depth $\left(a_{p}=20\right)$. The characteristic feature of this zone are the positive values of passive force. Zone B is the zone of static load of the tool, which is one of the main assumptions of the iMachining strategy. Due to the fact that machining in this zone is performed with the main cylindrical part of the milling cutter the cutting edges of which are distributed along the screw line, the resultant passive force takes the negative values. Zone $\mathrm{C}$ is for machining the corners. In this zone, the tool contact with the workpiece is interrupted, which is visible in the passive force run (visible moments of passive force return to the 0 value).

Three characteristic zones can also be observed for the machining performed by conventional strategy (Fig. 12). In zone A, the tool penetrates the material to the screw line. The characteristic feature of this zone are the positive values of passive force. In zone B, the tool starts machining at the depth of ap $=2 \mathrm{~mm}$, but there are sections in this zone in which the tool paths overlap, which results in the passive force return to zero. In zone $\mathrm{C}$, the machining at constant value of machining width $\mathrm{a}_{\mathrm{e}}$, and thus the constant force run within the entire zone can be observed.

The machining of the entire pocket required removal of material at 10 levels for the assumed machining depth $\mathrm{a}_{\mathrm{p}}=2 \mathrm{~mm}$ and the pocket depth of $20 \mathrm{~mm}$. The passive force run for 3 exemplary levels is presented in Figure 13.

By comparing the absolute values of passive force for two strategies applied, it can be noticed that the conventional machining has lower values of passive force.

a)

b)
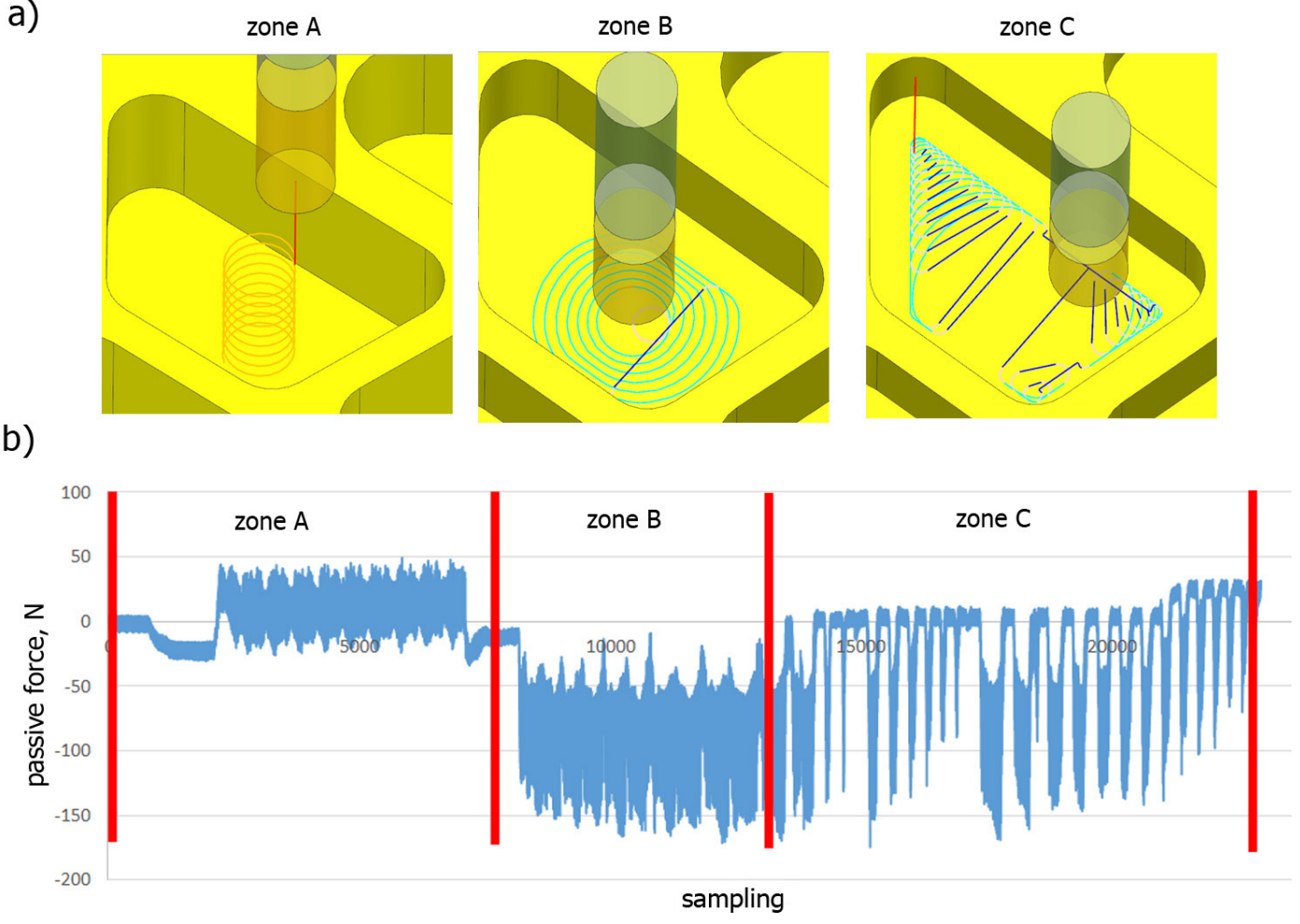

Fig. 11. Passive force run during different stages of machining with use of iMachining strategy: a) view of machining paths in particular zones, b) passive force run 
a)
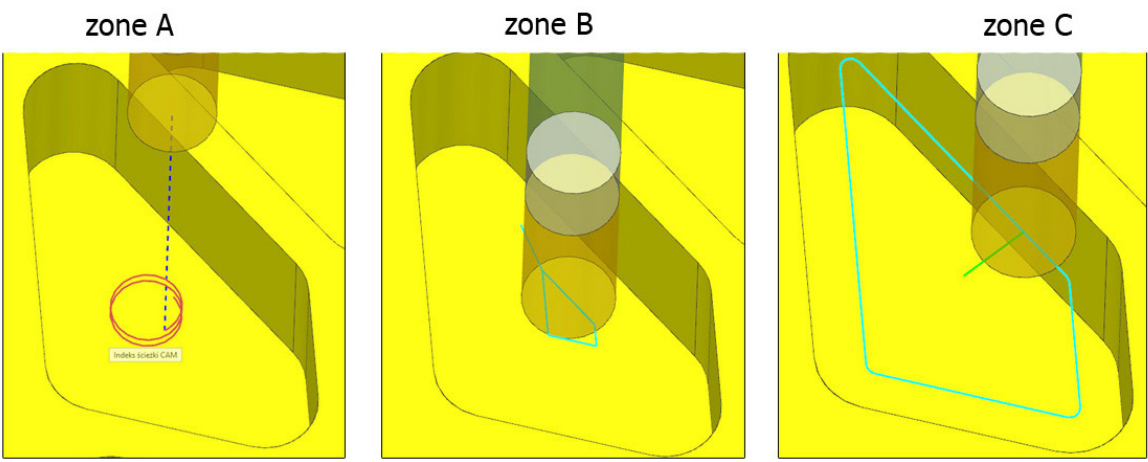

b)

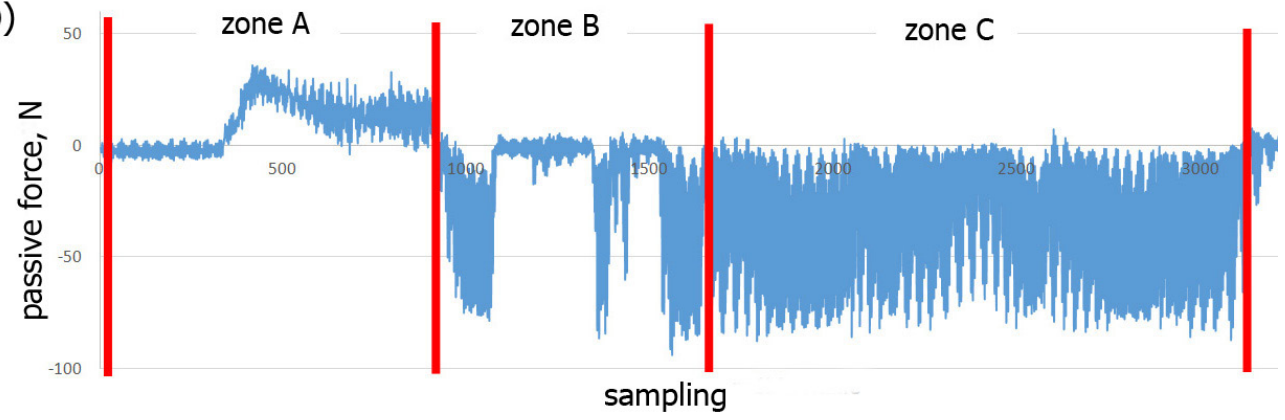

Fig. 12. Passive force run while machining of one level by conventional strategy:

a) view of machining paths in particular zones, b) passive force run
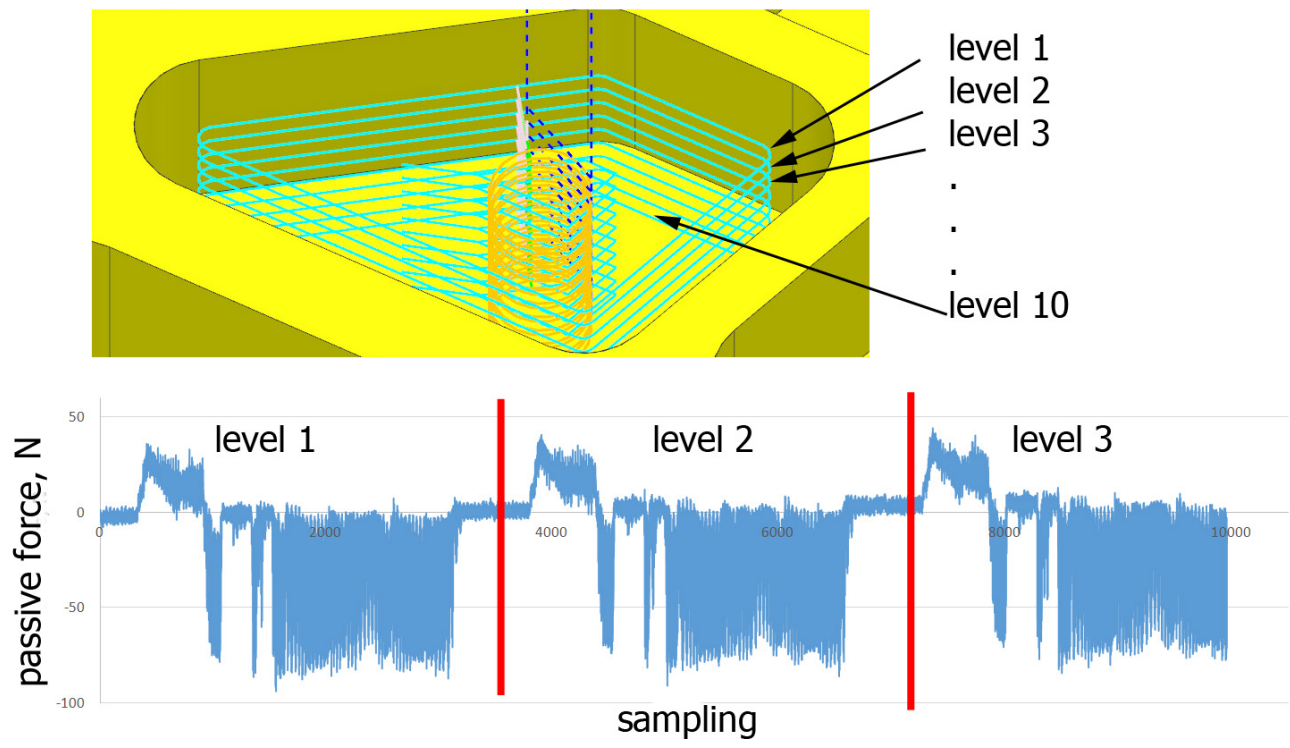

Fig. 13. Passive force run while milling at 3 machining levels

Figures 14 and 15 show the cutting torque run respectively for the iMachining strategy (Fig. 14) and the conventional strategy (Fig. 15). The highest values of cutting torque for the iMachining strategy (approx. 1.6 Nm) are observed in the zone $\mathrm{B}$, in which the working part is involved most.

For the conventional strategy, for each machining level, the torque run assumes a similar nature. The maximum transient value of cutting torque is approx. $0.8 \mathrm{Nm}$.

\section{CONCLUSIONS}

In this article, two machining strategies applied for the HSM process while milling the ENAW 70705 aluminium alloy were analysed. On the basis of the conducted experimental tests, the following conclusions can be drawn:

- A better use of the working part of a cutting tool while machining by iMachining strategy allows increasing the machining efficiency 


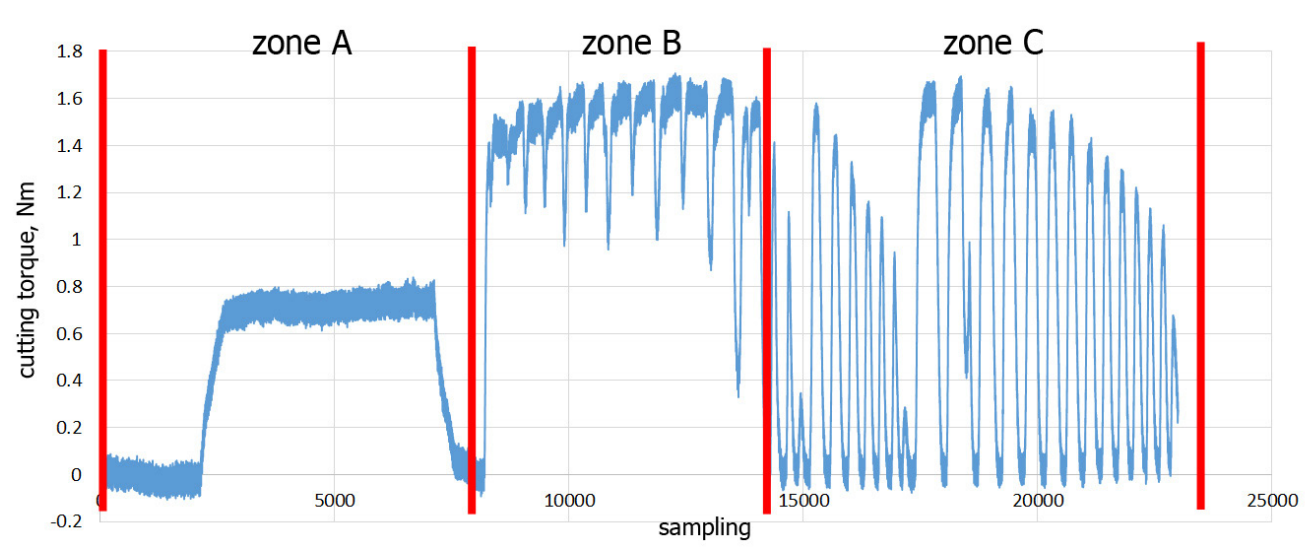

Fig. 14. Cutting torque while machining in acc. with iMachining strategy in particular zones

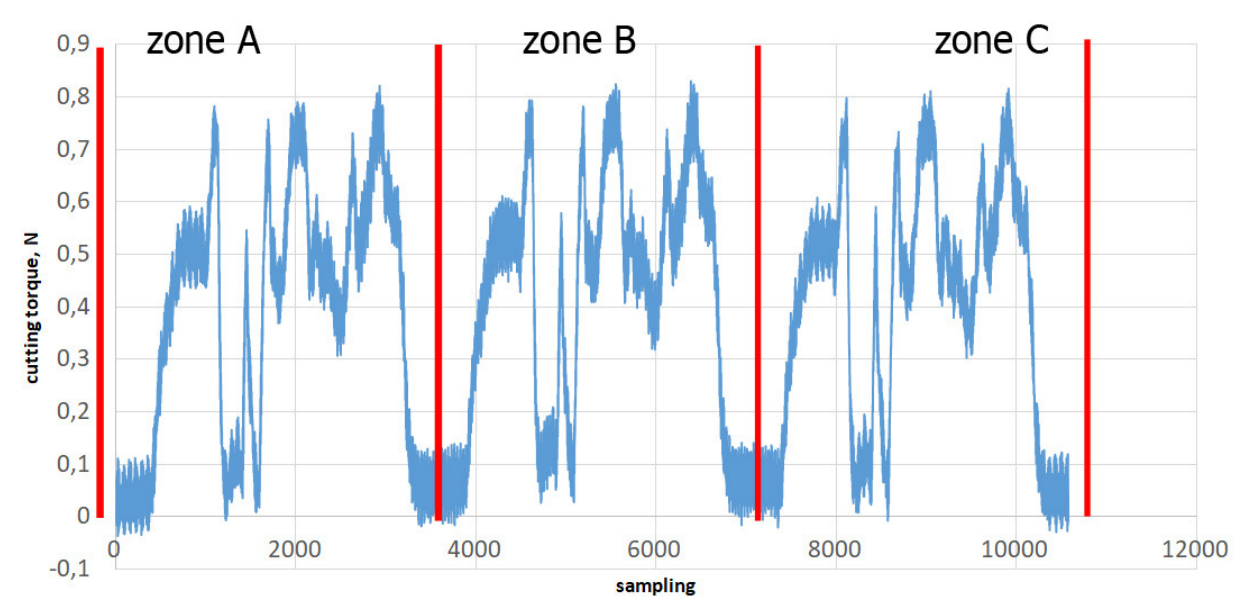

Fig. 15. Cutting torque run while milling at three machining levels in acc. with conventional strategy

volume by approx. $85 \%$ as compared to the conventional machining.

- A slightly lower values of roughness parameters $(\mathrm{Sa}$ and $\mathrm{Sz})$ were obtained for the machining performed in acc. with the iMachining strategy.

- During the conventional machining, the obtained values of chip volume factor $\mathrm{k}_{\mathrm{ch}}$ were halved, which allows to better use the collective containers in the production plant.

- A low value of factor $\mathrm{k}_{\mathrm{ch}}$ may cause problems with evacuation of chips from the machining zone during the HSM process, especially during the pocket structure machining.

- The values of passive force and cutting torque are lower in the case of the conventional machining.

- Upon analysing the force and cutting torque run when machining a closed pocket, it is possible to distinguish three characteristic stages of machining: tool penetration to the full machining depth, machining with constant tool load and machining of corners.

\section{Acknowledgements}

The project/research was financed under the project Lublin University of Technology-Regional Excellence Initiative, funded by the Polish Ministry of Science and Higher Education (contract No. 030/RID/2018/19).

\section{REFERENCES}

1. Kuczmaszewski, J., Zaleski, K., Matuszak, J., \& Mądry, J. (2019). Testing Geometric Precision and Surface Roughness of Titanium Alloy Thin-Walled Elements Processed with Milling. In Advances in Manufacturing II (pp. 95-106). Springer, Cham.

2. Michalik, P., Zajac, J., Hatala, M., Mital, D., \& Fecova, V. (2014). Monitoring surface roughness of thin-walled components from steel C45 machining down and up milling. Measurement, 58, 416-428.

3. Shan, C., Lv, X., \& Duan, W. (2016). Effect of tool inclination angle on the elastic deformation of thinwalled parts in multi-axis ball-end milling. Procedia CIRP, 56, 311-315. 
4. Luo, M., Luo, H., Zhang, D., \& Tang, K. (2018). Improving tool life in multi-axis milling of Ni-based superalloy with ball-end cutter based on the active cutting edge shift strategy. Journal of Materials Processing Technology, 252, 105-115.

5. Kuczmaszewski, J., Zaleski, K., Matuszak, J., Pałka, T., \& Mądry, J. (2017). Studies on the effect of mill microstructure upon tool life during slot milling of Ti6Al4V alloy parts. Eksploatacja i Niezawodność, Maintenance and Reliability, vol. 19, no. 4, 590-596.

6. Gologlu, C., \& Sakarya, N. (2008). The effects of cutter path strategies on surface roughness of pocket milling of 1.2738 steel based on Taguchi method. Journal of materials processing technology, 206(1-3), 7-15.

7. Toh, C. K. (2005). Design, evaluation and optimisation of cutter path strategies when high speed machining hardened mould and die materials. Materials \& design, 26(6), 517-533.

8. Toh, C. K. (2006). Cutter path strategies in high speed rough milling of hardened steel. Materials \& design, 27(2), 107-114.

9. Álvarez, Á., Calleja, A., Ortega, N., \& de Lacalle, L. (2018). Five-axis milling of large spiral bevel gears: toolpath definition, finishing, and shape errors. Metals, 8(5), 353.

10. Baohai, W. U., Ming, L. U. O., ZHANG, D., \& Feiyan, H. A. N. (2019). An automated approach to calculating the maximum diameters of multiple cutters and their paths for sectional milling of centrifugal impellers on a $4 \frac{1}{2}$-axis CNC machine. Chinese Journal of Aeronautics, 32(4), 1030-1039.

11. Calleja, A., Alonso, M. A., Fernández, A., Tabernero, I., Ayesta, I., Lamikiz, A., \& López de Lacalle, L. N. (2015). Flank milling model for tool path programming of turbine blisks and compressors. International Journal of Production Research, 53(11), 3354-3369.

12. Zagórski, I., Kulisz, M., Kłonica, M., \& Matuszak,
J. (2019). Trochoidal Milling and Neural Networks Simulation of Magnesium Alloys. Materials, 12(13), 2070.

13. Bawono, B., Anggoro, P. W., Bayuseno, A. P., Jamari, J., \& Tauviqirrahman, M. (2019). Milling strategy optimized for orthotics insole to enhance surface roughness and machining time by Taguchi and response surface methodology. Journal of Industrial and Production Engineering, 36(4), 237-247.

14. Wibowo, Y. T., Baskoro, S. Y., \& Manurung, V. A. (2018, February). Toolpath Strategy and Optimum Combination of Machining Parameter during Pocket Mill Process of Plastic Mold Steels Material. In IOP Conference Series: Materials Science and Engineering (Vol. 306, No. 1, p. 012137). IOP Publishing.

15. Etyemez, A. (2016). Optimization of Effects of Pocket Tool Path Strategies and Cutting

16. Zaujec, R., Vopát, T., Šimna, V., \& Pokorný, P. (2017). The influence of cam strategies on the tool wear and surface roughness. Annals of DAAAM \& Proceedings, 28.

17. Logins, A., \& Torims, T. (2015). The influence of high-speed milling strategies on 3D surface roughness parameters. Procedia Engineering, 100, 1253-1261.

18. Zagórski, I., \& Korpysa, J. (2019). Surface Quality in Milling of AZ91D Magnesium Alloy. Advances in Science and Technology. Research Journal, 13(2), 119-129.

19. Krolczyk, G., Legutko, S., \& Gajek, M. (2013). Predicting the surface roughness in the dry machining of duplex stainless steel (DSS). Metalurgija, 52(2), 259-262.

20. Fulemova, J., Hnatik, J., Kozmin, P., Sklenicka, J. Influence of cooling methods on tool life during machining with iMACHINING strategy (2015) Proceedings of the International Conference of DAAAM Baltic "Industrial Engineering", 2015-January, pp. 15-20. 